\title{
Cultuursociologie in de Lage Landen
}

\author{
Julian Schaap, Koen van Eijck en Janna Michael
}

SOC $14(2 / 3): 75^{-85}$

DOI: 10.5117/SOC2018.2/3.001.SCHA

In juni 2017 organiseerde de programmagroep Culturele Sociologie aan de Universiteit van Amsterdam een bijeenkomst onder de noemer Cultural Sociology Lowlands, met als doel cultuursociologen in Nederland en Vlaanderen te verenigen en onderlinge intellectuele uitwisseling te stimuleren. In hun uitnodiging voor de bijeenkomst gaven de organisatoren aan een brede opvatting van culturele sociologie ${ }^{1}$ te hanteren: 'van onderzoek naar morele en esthetische standaarden, de productie en consumptie van kunst en cultuur, maar ook emoties, en meer of minder alledaagse praktijken of verschijnselen zoals voeding, mobiliteit, seksualiteit, mediagebruik en geweld'. Waar dit voor hen die zich identificeren als cultuursocioloog wellicht een kraakheldere begripsbepaling betreft, zal menig sociaalwetenschapper - laat staan leken - weinig wijs kunnen uit deze brede definitie. Inderdaad, een veelheid aan onderwerpen passeerde de revue tijdens deze intensieve tweedaagse bijeenkomst en er leek geen balkanisering rond onderwerpen op te treden: experts op het gebied van genderongelijkheid haakten prima aan bij thematiek over religieuze zingeving, kwalitatieve onderzoekers becommentarieerden met verve hun kwantitatieve vakgenoten en vice versa. Desondanks was de eerste vraag die een jonge promovendus stelde aan eregast Omar Lizardo: 'wat is cultuursociologie eigenlijk?'

Voor $\mathrm{u}$ ligt een themanummer dat geheel is gewijd aan de NederlandsVlaamse cultuursociologie, een vakgebied binnen de sociologie - maar eigenlijk ook de bredere sociale wetenschappen - dat al jaren een sterke aanwezigheid kent aan een aantal universiteiten in de Lage Landen. Dat blijkt onder andere uit het feit dat de eerste Cultural Sociology Lowlands bijeenkomst inmiddels is opgevolgd door edities in Leuven en Rotterdam, met Brussel op de planning voor 2019. Ook dit rijk gevulde themanummer 
is een gevolg van deze productieve bijeenkomsten. Zoals valt af te lezen aan de titels en samenvattingen van de verschillende artikelen, lopen zowel de besproken thema's als de gebruikte methodologieën sterk uiteen. Wij vonden het als gastredactie belangrijk om de verschillende perspectieven in de cultuursociologie samen te brengen en de kracht van cultuursociologische verklaringen in hun diversiteit te tonen. Vaak publiceren cultuursociologen hun werk in tijdschriften van andere (sub)disciplines en doen ze dat bij voorkeur in het Engels. Dit themanummer is dus ook een poging om waardevol cultuursociologisch werk 'naar huis' te halen en toegankelijk te maken in het Nederlands.

Cultuursociologie heeft misschien geen breed gedeelde visie, geen doxa, zoals Kobe De Keere stelt in zijn essay in dit themanummer, maar de vraag is of dat überhaupt nodig is: het lijkt er op dat de noodzaak voor een definitie hoofdzakelijk bedoeld is voor hen buiten de cultuursociologie. Zo stellen Alexander, Jacobs en Smith (2012:5) dat de discipline zelden doet aan positionering maar juist 'gets on with explaining stuff, or with developing tools to do this explaining'. Met andere woorden, 'broad calls for legitimation do not reflect routine practice but rather are appeals to an imagined audience of outsiders' (ibid.). Maar dat pragmatisme stelt ons voor een dilemma; hoe graag wij ook gauw tot de inhoud willen komen, Sociologie is een tijdschrift waarvan het brede lezerspubliek minder 'imagined' is dan Alexander et al. stellen. Een degelijke inleiding van dit themanummer kan dus niet zonder een introductie in de cultuursociologie en haar vele gezichten. Ook hier geldt dat de cultuursociologische bijdragen aan de sociale wetenschappen dusdanig divers zijn dat de 'task of explaining the merits of these contributions for the consolidation of cultural sociology is restricted to the editors' introductions' (Lima Neto 2014: 938). Daarom, een korte introductie in de cultuursociologie.

\section{Cultuursociologie, culturele sociologie, sociologie van cultuur...}

Afgaande op het aantal (soms vuistdikke) handboeken dat is gepubliceerd over cultuursociologie (bijvoorbeeld Alexander, Jacobs en Smith 2012; Hall, Grindstaff en Lo 2010; Hanquinet en Savage 2016; Inglis en Almila 2016; Spillman 2002; Wray 2014) lijkt het een duidelijk omlijnd vakgebied. Deze handboeken hanteren doorgaans een globale tweedeling van cultuursociologische deelgebieden, die samenhangen met de verschillende percepties van de rol en betekenis van het concept 'cultuur': één als afhankelijke 
variabele en één als onafhankelijke variabele. In beide gevallen staat betekenis centraal: hoe mensen betekenis geven aan het leven en deze in stand houden door middel van, of in de vorm van, cultuur.

Als 'afhankelijke variabele' is cultuur - soms als onderdeel van 'kunst en cultuur' - het object van sociologische interesse. In dit geval gaat het om de materiële en immateriële uitingen van mensen zoals muziek, boeken, theaterstukken, internet memes en schilderijen. Die uitingen - en de waardering ervoor - zijn in deze variant afhankelijk van geldende sociale structuren. Deze 'cultuur' in enge zin, of 'cultuur met een grote C', wordt doorgaans bestudeerd vanuit de klassieke geesteswetenschappen zoals literatuurstudies of musicologie. In de sociologie wordt dit perspectief vaak (maar lang niet altijd) onderscheiden van cultuursociologie door het te benoemen als 'sociologie van (kunst en) cultuur', of wordt het onder de vlag van 'cultuurwetenschap' geplaatst. Mede hierdoor wordt dit perspectief nogal eens gelieerd aan het Britse cultural studies, dat - om het geheel nog complexer te maken - een andere epistemologische aanpak behelst dan de sociologie van (kunst en) cultuur. Mede door de vaak expliciet politiekactivistische houding van beoefenaars van cultural studies, positioneren sociologen zich doorgaans als meer waardevrij en dus gedifferentieerd van hun (veelal Britse) collega's (Lima Neto 2014: 933). Ook zijn de dominante, op literatuurstudies gestoelde methodologieën van hermeneutische (her) interpretatie van 'tekst', niet erg populair in het meer positivistische sociologische methodenlandschap (Rojek en Turner 2000).

De sociologie van (kunst en) cultuur is niet anders dan andere 'sociologie van ...'-varianten. Zo legt Victoria Alexander in haar veelgebruikte handboek Sociology of the Arts (2003: 1) uit dat:

We will examine how groups of people work together to create what we call art. We will look at why some things are called 'art' and some people 'artists', and why other things and people are not. We will look at the meaning of artistic objects and why interpretations of art vary. We will look at how people use artistic products, for aesthetic pleasure certainly, but also for other reasons. And we will study the intersection of race, gender, and class with art.

Zoals te zien in deze taakomschrijving, wordt er een koppeling gemaakt tussen sociale structuren (bijvoorbeeld de definitie van arbeid, of stratificatie op basis van klasse) en de productie en consumptie van kunst. Vanuit dit perspectief bezien, spelen kunst en cultuur een essentiële rol in alledaagse betekenisgeving en dus ook in het maatschappelijk leven, maar zijn zij in essentie afhankelijk van onderliggende structurele krachten. Een bekende 
pleitbezorger van dit perspectief was Richard Peterson met zijn production of culture-aanpak (Peterson en Anand 2004), waarmee hij wees op het belang van onder andere sociale, institutionele, economische en technologische factoren die fundamenteel zijn voor het ontstaan van cultuur.

In deze onderzoekslijn wordt 'cultuur' ook vaak beschouwd als kenmerk van specifieke groepen - het idee dat er overeenkomsten zijn tussen leden van groepen (bijvoorbeeld 'Nederlanders', 'boeddhisten' of 'motorbendes') in hoe zij de wereld bekijken, hoe zij beoordelen en hoe zij handelen. Daarom rekenen Jeffrey Alexander en Philip Smith (2001) het werk van Bourdieu ook tot deze lijn. In dat werk zien zij cultuur, via de habitus, vooral werkzaam als instrument in de reproductie van sociale ongelijkheid en veel minder als een autonome kracht die tot innovatie leidt. Anders dan bij Weber, is de culturele inhoud die Bourdieus statusgroepen kenmerkt bovendien arbitrair zolang deze maar als legitiem wordt erkend. De grote invloed van Bourdieus oeuvre heeft er wellicht toe geleid dat veel (cultuur) sociologen vooral vertrouwd zijn met deze opvatting van de rol van cultuur in sociologie en samenleving. Wanneer er wordt gesproken over de 'multiculturele samenleving' of 'cultureel verschil' is het dan ook deze definitie van cultuur die geldt; het idee dat er verschillende - van elkaar te onderscheiden - 'culturen' zijn die horen bij bepaalde groepen en als te verklaren fenomenen centraal kunnen staan in onderzoek.

Cultuur als 'onafhankelijke variabele' betreft datgene dat al het menselijk handelen fundeert. Dit perspectief is op de agenda gezet door Jeffrey Alexander (2003) in wat het strong program of de 'Yale-aanpak' is gaan heten. Volgens Alexander ligt cultuur - in brede zin - ten grondslag aan al het menselijk handelen waardoor het onderdeel vormt van de sociale structuur. Cultuur is autonoom. Daarmee positioneert Alexander zichzelf tegenover de sociologie van (kunst en) cultuur, met name Peterson, want 'to speak of the sociology of culture is to suggest that explanatory power lies in the study of the "hard" variables of social structure, such that structured sets of meanings become superstructures and ideologies driven by these more "real" and tangible social forces' (Alexander 2003: 13).

Hoewel de verschillende perspectieven soms ferm tegenover elkaar worden gesteld, blijkt de cultuursociologische praktijk vaak een stuk minder rechtlijnig. Neem nu, opnieuw, het werk van Bourdieu, die de habitus typeert als zowel sociaal gestructureerde structuur (afhankelijk van het sociale domein) als een structurerende structuur (die het sociale domein beïnvloedt). Juist in die mediërende rol ligt de kracht van het concept en daarom kan de habitus, en daarmee cultuur, ook in de bourdieuiaanse benadering een verklarende, zij het niet geheel autonome, rol spelen in 


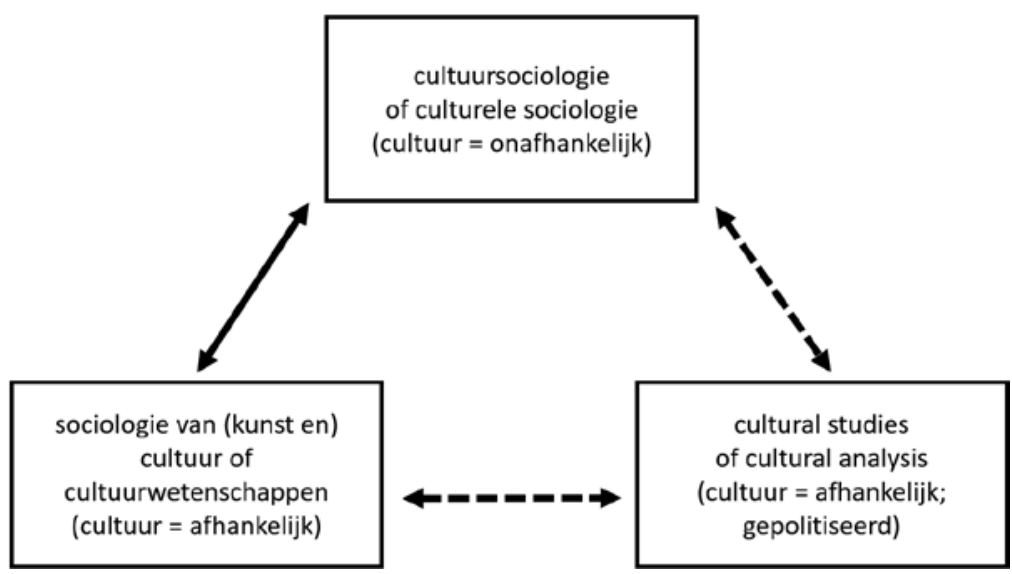

Figuur 1 Cultuursociologie, sociologie van (kunst en) cultuur, en cultural studies

theorie en onderzoek (zie ook Van Eijck en Michael 2013). Dat gegeven leidt in de praktijk tot weinig ongemak, omdat er brede consensus bestaat over het belang van betekenisgeving in beide perspectieven, gestoeld op de 'cultural turn' die plaatsvond in de sociale wetenschappen in de jaren tachtig van de vorige eeuw. Een blik op de verschillende handboeken en inleidingen laat ook exact dat zien. Sommige auteurs houden het simpel. Zo stelt Lyn Spillman in Cultural Sociology (2002: 1): 'Cultural sociology is about meaning-making. Cultural sociologists investigate how meaning-making happens, why meanings vary, how meanings influence human action, and the ways meaning-making is important in social cohesion, domination, and resistance'. Wellicht is het echter nauwkeuriger om te spreken over het in stand houden van betekenis in plaats van het creëren van betekenis, aangezien 'an individual behaves not just to maintain the meaning of self, but to maintain understandings generally - humans are meaning-maintainers' (Heise 2002: 36$){ }^{2}$ Linksom of rechtsom, het ontstaan van cultuursociologie is in essentie niets anders dan de ontwikkeling van een sociologie waar betekenis centraal staat, die 'meaning-aware' is (Alexander et al. 2012: 4).

Hoewel de cultural turn gold voor de sociale en geesteswetenschappen in het algemeen, is cultuursociologie het meest concrete overblijfsel van deze ontwikkeling. Ook over de reden van het bestaan zijn handboeken dus vrij unaniem: cultuursociologen 'give weight to aspects and dimensions of social life that have received little or marginal consideration from previous generations of sociologists' (Back et al. 2012: xi). De cultuursociologen en sociologen van (kunst en) cultuur zitten elkaar dus niet zo in de weg. Inderdaad: 'cultural sociology is not a particular position but 
refers to a broad field encompassing all sociological positions vis-a-vis culture' (Lima Neto 2014: 933). Sociologisch, dus cultural studies blijft wel op afstand.

Als vaandeldragers in de strijd om aandacht voor de 'blinde vlek voor cultuur' (Houtman 2000) - zowel als afhankelijke en als onafhankelijke variabele - bewegen cultuursociologen zich dus met relatief gemak tussen verschillende disciplines. Hoewel wellicht een hoofdpijndossier voor de klassieke, naar specialismen opgedeelde universitaire afdelingen, voelen cultuursociologen vaak weinig schroom om richting andere disciplines te bewegen. Zo laat Giselinde Kuipers in haar scherpe essay in deze bundel zien dat cultuursociologen om deze reden relatief goed vertegenwoordigd zijn binnen afdelingen mediastudies. Dat betekent nog niet dat er voldoende oog is voor de (cultuur)sociologische consequenties van het proces van mediatisering, dat bezig is de samenleving te veranderen op een manier die vermoedelijk fundamenteler is dan wij ons realiseren. Sterker, Kuipers ontwaart een sociologische blinde vlek voor media en ziet een grote rol weggelegd voor cultuursociologen die bij uitstek bezig zijn met betekenissystemen, die in de regel gemediatiseerd zijn, alsook met mediëring in bredere zin.

De door Kuipers bepleite bemoeienis van cultuursociologen met mediastudies maakt, evenals het essay van De Keere, duidelijk dat cultuursociologie zich niet in een niche kan en mag opsluiten. Dat gebeurt ook niet, cultuursociologen publiceren niet uitsluitend in specialistische bladen (waar er ook maar een paar van zijn: het Britse Cultural Sociology, het Amerikaanse 'strong program' American Journal of Cultural Sociology en het oorspronkelijk sterk literatuurwetenschappelijke Poetics), maar overal waar zij kunnen. Al bricolerend met methodologieën en onderzoeksthema's zijn zij te vinden in tijdschriften voor disciplines zo divers als gezondheidswetenschappen (bijvoorbeeld Oude Groeniger et al. 2017) of watertechnologie (bijvoorbeeld De Koster en Achterberg 2015). Veel minder zien we dat cultuursociologische theorieën toegepast worden door wetenschappers buiten het veld, als we het publiceren van niet-cultuursociologen in cultuursociologische tijdschriften als maatstaf hanteren. Bovendien zijn zelfs sociologen, met name in Nederland, vaak wars van de cultuursociologische benadering (voor een bespreking, zie Houtman 2009). In die zin lijkt cultuursociologie op het eerste gezicht niet meer dan een 'subdiscipline situated at the intersection of other discipines and subdisciplines' (Lima Neto 2014: 940). Maar, zoals De Keere in zijn essay laat zien, het is meer dan dat. 


\section{Nut en noodzaak van cultuursociologie}

Ondanks het feit dat cultuursociologie inmiddels een stabiele aanwezigheid heeft in de sociale wetenschappen, wordt de benadering in beschouwende teksten over het vakgebied nogal eens gekenschetst als 'in opkomst' (zie bijvoorbeeld Lima Neto 2014: 928-929). Dat zal deels te maken hebben met het gebrek aan interne eenduidigheid binnen het vakgebied, wat de externe zichtbaarheid bemoeilijkt. Ongetwijfeld maken de vele wetenschapsgebieden die zich met cultuur bezighouden het er niet overzichtelijker op. Maar bovenal lijkt dit het gevolg te zijn van de rol die cultuursociologen zichzelf al decennia toedichten: wijzen op het belang van cultuur, terwijl dit doorgaans geen of slechts een ondergeschikte rol krijgt toebedeeld in sociologisch onderzoek.

Ook in dit themanummer zien we dit terugkeren. Marcel van den Haak onderzoekt uit welke esthetische repertoires mensen putten wanneer zij hun culturele smaken bespreken. Hij laat zien dat de bredere smaak van hoger opgeleiden wordt geschraagd door een scala van esthetische criteria. Van den Haak toont aan dat - omdat hoogopgeleiden zowel puur esthetische als populaire criteria gebruiken - het onderscheid tussen hoge en populaire cultuur niet alleen in gedrag wordt overschreden door de zogenaamde omnivoren, maar ook samenhangt met wat we zouden kunnen omschrijven als een meer flexibele, meervoudige of contextafhankelijke habitus dan Bourdieu voor ogen had (zie ook Bennett et al. 20o9; Lahire 2011). In de vorm van cultuur bepalen disposities hoe we de wereld om ons heen interpreteren, maar de mate waarin die cultuur een strak keurslijf vormt, verschilt tussen sociale groepen.

Katerina Manevska, Peter Achterberg en Dick Houtman wijzen op het belang van cultureel aangestuurde contactselectie tussen mensen, een factor die grotendeels is genegeerd in de brede literatuur over interetnisch contact. Hier wordt over het algemeen verondersteld dat meer interetnisch contact leidt tot minder vooroordelen over etnische groepen (contacttheorie). De auteurs attenderen ons echter op de waarschijnlijkheid van een omgekeerd causaal proces van etnische vooroordelen naar interetnisch contact. Daarnaast houden ze rekening met de rol van cultuur in de wijze waarop mensen interetnische contacten interpreteren. Door cultuur mee te nemen in de analyse - met opleidingsniveau als proxy - blijkt dat de contacttheorie vooral geldt voor hoger opgeleiden. Bovendien laten zij op deze wijze zien dat, in tegenstelling tot wat vaak wordt gedacht, minder vrijwillig gekozen interetnische interacties bestaande attitudes jegens etnische minderheden versterken. 
Ook Roy Kemmers legt in dit nummer een klassieke theorie op de pijnbank: de kanaliseringsthese, welke postuleert dat een stem op een populistische partij vooral functioneert als een gelegenheid om frustratie te uiten over het dominante politieke bestel. Zo'n stem zou leiden tot een gevoel van voldoening, niet anders dan het afblazen van stoom. Door in gesprek te gaan met niet-stemmers en aanhangers van Geert Wilders' Partij voor de Vrijheid (PVV), toont Kemmers aan dat de kanaliseringsthese lang niet altijd opgaat voor aanhangers van populistische partijen. Hoe burgers conceptualiseren waar 'de macht' precies ligt in de maatschappij - 'machtsorientatie' - blijkt te interveniëren in dit proces. Deze cultuursociologische gevoeligheid voor de culturele dimensies van politieke perceptie levert een bruikbaar concept op dat inmiddels ook kwantitatief is gestaafd (Driessen en Kanne 2018).

Juist doordat cultuursociologen het begrip 'cultuur' constant herdefinieren en verder uitdiepen, ontstaat er om de zoveel tijd een noodzaak voor het ontwikkelen van nieuwe, innovatieve methodologieën. Geplaatst voor de sociologische puzzel dat aanhangers van populistisch radicaal-rechtse partijen vaak zowel conservatieve als progressieve culturele opvattingen huldigen, maken Stijn Daenekindt, Willem de Koster en Jeroen van der Waal in dit nummer gebruik van Correlationele Klasseanalyse; een innovatieve methodologie om inductief stelsels van opvattingen op te diepen. Uit hun analyse blijkt dat structuren van opvattingen - bijvoorbeeld langs lijnen van 'progressieve' tegenover 'conservatieve' stelsels van attitudes vaak veel minder homogeen zijn dan doorgaans wordt verondersteld (vergelijk ook Van den Haaks conclusie). In de praktijk zijn deze stelsels vaak quasi-gestructureerd of versplinterd in plaats van geïntegreerd. Het zijn de cultuursociologische gevoeligheid voor cultuur als verklarende variabele en de openheid voor methodologische innovatie die er toe leiden dat zij kunnen stellen dat 'dit opmerkelijke fenomeen tot op heden onopgemerkt is gebleven'.

Zoals De Keere bespreekt in zijn essay, is er de laatste jaren ook in toenemende mate werk gemaakt van het realiseren van een meer cognitieve cultuursociologie, aangevoerd door bekende cultuursociologen zoals Karen Cerulo (2002), Paul DiMaggio (1997), Michele Lamont (Lamont et al. 2017) en Omar Lizardo (2004). Ook is er een groeiende belangstelling voor de manieren waarop mensen hun aandacht verdelen in het ordenen van de sociale realiteit. Zo wijzen cognitieve sociologen zoals Eviatar Zerubavel (1997) en Wayne Brekhus (2015) op het belang van 'cognitieve asymmetrie': de neiging van mensen om meer aandacht te schenken aan dat wat sociaal wordt 'gemarkeerd' tegenover een 'ongemarkeerde' maar dominante 
normcultuur. Door in zowel een kwantitatieve als kwalitatieve inhoudsanalyse aandacht te schenken aan dit proces van sociale markering, laten Julian Schaap en Pauwke Berkers zien hoe de symbolische 'witheid' van rockmuziek in stand wordt gehouden (maar ook wordt bevochten) door consumenten en professionele muziekrecensenten. Niet alleen blijkt dat bands met (hoofdzakelijk) niet-witte bandleden gemiddeld lager worden geëvalueerd dan hun witte vakgenoten, ook worden zij vaker met elkaar vergeleken of gepositioneerd rond andere, 'zwarte' genres zoals hip-hop en soul. Ook hier is de benadering fundamenteel cultuursociologisch: etnoraciaal onderscheid wordt niet veroorzaakt door racistische fanatici maar door hoe mensen in het dagelijks leven de sociale realiteit ordenen langs, onder andere, etno-raciale lijnen. Cultuursociologie als debunking discipli$n e$ laat zich in al deze artikelen weer van haar sterkste kant zien.

We blijven dus drammen, in de hoop dat andere disciplines - waaronder in de bredere sociologie zelf - cultuur, zowel als afhankelijke als onafhankelijke variabele, serieuzer gaan nemen. Ironisch genoeg zou dat het risico met zich mee kunnen brengen dat het vakgebied zichzelf om zeep helpt. Met andere woorden, wellicht is de cultuursociologie pas echt geslaagd als zij zichzelf moet opheffen omdat andere disciplines het belang van cultuur zijn gaan inzien. Maar gezien de veelheid aan thema's, disciplines en methodologieën waar cultuursociologen zich op storten, en de terughoudendheid van hen daarbuiten om cultuur als volwaardig te beschouwen, lijkt die kans vooralsnog erg klein. ${ }^{3}$

\section{Noten}

1 Hoewel we veel verschillende variaties op de studie van cultuur tegenkomen in deze inleiding, is er - zover wij weten - geen fundamenteel onderscheid tussen 'culturele sociologie' en 'cultuursociologie'. Wij kiezen hier voor de laatstgenoemde term.

2 Patterson (2014: 7-8) stelt hierover terecht de vraag: 'Shared meanings are made and changed $[. .$.$] but not in the compulsive, cognitively exhausting manner proposed by$ many conventional cultural sociologists, to whom I pose this simple question: Beyond the seminar room, when last did you make a meaning in your interactions?'

3 En anders is er uiteraard nog de sociologie van (kunst en) cultuur. 


\section{Literatuur}

Alexander, J.C. (2003) The meanings of social life: A cultural sociology. Oxford: Oxford University Press.

Alexander, J.C. en P. Smith (2001) The strong program in cultural theory: Elements of a structural hermeneutics. In: J.H. Turner (red.) Handbook of sociological theory. Boston: Springer, 135-150.

Alexander, J.C., R.N. Jacobs en P. Smith (2012) The Oxford handbook of cultural sociology. Oxford: Oxford University Press.

Alexander, V. (2003) Sociology of the arts: Exploring fine and popular forms. Malden: Blackwell.

Back, L., A. Bennett, L. Desfor Edles, M. Gibson, D. Inglis, R. Jacobs en I. Woodward (red.) (2012) Cultural sociology: An introduction. Malden: Wiley-Blackwell.

Bennett, T., M. Savage, E. Silva, A. Warde, M. Gayo-Cal en D. Wright (2009) Culture, class, distinction. London: Routledge.

Brekhus, W.H. (2015) Culture and cognition: Patterns in the social construction of reality. Cambridge: Polity Press.

Cerulo, K.A. (red.) (2002) Culture in mind: Toward a sociology of culture and cognition. New York: Routledge.

DiMaggio, P. (1997) Culture and cognition. Annual Review of Sociology, 23(1): 263-287.

Driessen, M. en P. Kanne (2018) Versterking lokale democratie. Rapport in opdracht van het ministerie van Binnenlandse Zaken en Koninkrijksrelaties, rapportnummer 2018/89. Amsterdam: I\&O Research.

Eijck, K. van en J. Michael (2013) Culturele consumptie en de habitus: De rol van kennis en esthetische disposities. Mens en Maatschappij, 88(1): 63-89.

Hall, J.R., L. Grindstaff en M. Lo (2010) Handbook of cultural sociology. London: Routledge.

Hanquinet, L. en M. Savage (red.) (2016) Routledge international handbook of the sociology of art and culture. London: Routledge.

Heise, D. (2002) Understanding social interaction with affect control theory. In: J. Berger en M. Zelditch (red.) New directions in sociological theory. Boulder: Rowman \& Littlefield, 17-40.

Houtman, D. (2000) Een blinde vlek voor cultuur: Sociologen over cultureel conservatisme, klasse en moderniteit. Assen: Van Gorcum.

Houtman, D. (2009) Een halve eeuw na Moderne sociologie (1959): J.A.A. van Doorn is dood en de sociologie voelt zich niet zo lekker. Sociologie, $5(4): 5^{21-539}$.

Inglis, D. en A. Almila (red.) (2016) The SAGE handbook of cultural sociology. Los Angeles: Sage.

Koster, W. de en P. Achterberg (2015) Commentaar op "Providing information promotes greater public support for potable recycled water" door K.S. Fielding en A.H. Roiko (Water Research, 61: 86-96). Water Research, 84: 372-374.

Lahire, B. (2011) The plural actor. Cambridge: Polity Press.

Lamont, M., L. Adler, B.Y. Park en X. Xiang (2017) Bridging cultural sociology and cognitive psychology in three contemporary research programmes. Nature Human Behaviour, 1(12): 866-872.

Lima Neto, F. (2014) Cultural sociology in perspective: Linking culture and power. Current Sociology Review, 62(6): 928-946.

Lizardo, O. (2004) The cognitive origins of Bourdieu's habitus. Journal for the Theory of Social Behaviour, 34(4): 375-401.

Oude Groeniger, J., F.J. van Lenthe, M.A. Beenackers en C.B. Kamphuis (2017) Does social distinction contribute to socioeconomic inequalities in diet: The case of 'superfoods' consumption. International Journal of Behavioral Nutrition and Physical Activity, 14(1): 40.

Patterson, O. (2014) Making sense of culture. Annual Review of Sociology, 40: 1-30. 
Peterson, R.A. en N. Anand (2004) The production of culture perspective. Annual Review of Sociology, 30: 311-334.

Rojek, C. en B. Turner (200o) Decorative sociology: Towards a critique of the cultural turn. The Sociological Review, 48(4): 629-648.

Spillman, L. (red.) (2002) Cultural sociology. Malden: Blackwell.

Wray, M. (2014) Cultural sociology: An introductory reader. New York: W.W. Norton.

Zerubavel, E. (1997) Social mindscapes: An invitation to cognitive sociology. Cambridge: Harvard University Press.

\section{Over de auteurs}

Julian Schaap is cultuursocioloog en als postdoctoraal onderzoeker en docent werkzaam aan het Department of Public Administration and Sociology, Erasmus Universiteit Rotterdam. Daar doet hij (onder andere) onderzoek naar sociale ongelijkheid, milieuspecifieke levensstijlen en populaire muziek. Hij is tevens redacteur van Sociologie.

E-mail: schaap@essb.eur.nl

Koen van Eijck is hoogleraar Culturele Leefstijlen aan de afdeling Cultuurwetenschappen van de Erasmus Universiteit Rotterdam. Hij doet onder meer onderzoek naar smaakpatronen, ongelijkheid in cultuurparticipatie, kunstwaardering (muziek en beeldende kunst) en artistieke talentontwikkeling.

E-mail:vaneijck@eshcc.eur.nl

Janna Michael is cultuursocioloog en als postdoctoraal onderzoeker en docent werkzaam aan de afdeling Cultuurwetenschappen van de Erasmus Universiteit Rotterdam. Ze heeft gepubliceerd over culturele consumptie in relatie met ongelijkheid, levensstijlen en ironie. Nu houdt zij zich bezig met onderzoek naar cultuurparticipatie en de gamificatie van klassieke muziek. E-mail:michael@eshcc.eur.nl 
